\title{
A NEW GENUS OF PONERINE ANTS FROM WEST AFRICA (HYMENOPTERA: FORMICIDAE) WITH ECOLOGICAL NOTES
}

\author{
By William L. Brown, Jr. ${ }^{1}$, William H. Gotwald, Jr. ${ }^{2}$, \\ AND JEAN LÉvieux ${ }^{3}$
}

During work in recent years in the Ivory Coast, one of us (Jean Lévieux) has collected 4 colonies and colony-fragments of an extraordinary small ponerine ant belonging to a new genus apparently related to Amblyopone, but having the petiole separated from the postpetiole by a deep vertical constriction. The formal description of this genus and species is offered below.

The characterization is greatly enhanced by scanning electron micrographs (Plates I, II) taken by Prof. Howard E. Hinton of the University of Bristol, England, for whose generosity we are most grateful.

\section{Apomyrma genus nov.}

Worker: Habitus in life and to the naked eye much that of a very small, slender, shining Amblyopone. Also reminiscent of Leptanilla.

Head oblong, depressed, parallel-sided, with rounded corners (like that of many female pristocerine Bethylidae), anterior corners of head unarmed. Eyes and ocelli lacking. Antennae r 2-segmented, scapes very short and clavate, funiculus robust, with an indistinct 4-merous club. Antennal sockets round, impressed, completely exposed, the frontal carinae extremely reduced and indistinguishably fused with the reduced median portion of the clypeus to produce a small, subtriangular tumulus or convex platform that trails a brief septum posteriad scarcely beyond the level of the posterior socket

\footnotetext{
${ }^{1}$ Department of Entomology, New York State College of Agriculture at Cornell University, Ithaca, New York 14850, USA.

${ }^{2}$ Department of Biology, Utica College of Syracuse University, Utica, New York 13502, USA.

${ }^{3}$ Laboratoire de Zoologie, École Normale Supérieure, Paris V, France. Research and publication aided by grants nos. 5574X and 24822 from the U. S. National Science Foundation to William L. Brown, Jr., principal investigator. Research of Jean Lévieux supported in large part by the Centre National de Recherche Scientifique de France.

Manuscript received by the editor November 2, 1970.
} 
rims (see Fig. 5). Clypeus, except for the small raised median portion, impressed, very narrow and not distinctly demarcated behind, its anterior border shallowly but broadly concave, unarmed. The basal part of the labrum forms a straight line within the clypeal concavity, and bears a row (actually backed by a second row) of peg-like teeth that seem at first sight to spring from the clypeal margin. These teeth fill the narrow space between the clypeus and the normally closed mandible. Mandibles short, gently curved, and linear, with bidentate apex and a few blunt, spaced teeth on apical half of inner border. Labrum broader than long, sides converging distad; apex broadly emarginate; extensor surface with two irregular rows of peg-like teeth (or modified hairs) on basal half. Maxilla simplified from form of Amblyopone pallipes (see Gotwald, 1969), without galeal comb, and galeal crown smoothly continuing the dorsal galeal margin; maxillary palpus 2-segmented. Labium apparently without paraglossal lobes; setae of subglossal brushes tapered to apices; labial palpi 2-segmented.

Truncus $(=$ alitrunk, $=$ thorax + propodeum $)$ long and slender, consisting of a convex, immarginate pronotum into which is flexibly fitted a slightly longer oblong portion consisting mainly of propodeum, meso- and metathorax; mesonotum reduced to a narrow,.. depressed transverse strip largely covered by posterior edge of pronotum except when pronotum is flexed downward. Propodeal dorsum almost flat (weakly convex), immarginate but with pleura perpendicular; declivity strongly convex, immarginate and unarmed, overhanging lower part and orifice. Bulla of metapleural gland conspicuously outlined through cuticle, subcircular; propodeal spiracle contiguous with it anteriad. Coxae nearly the same size (anterior coxa largest); femora short and strongly incrassate toward their middle; tarsi short, slender at base but gradually becoming thicker to near their apices. Tibial spurs $\mathrm{I}, 2,2$, the middle and posterior legs each with one large, broadly pectinate inner spur and a smaller, more slender, sparsely pectinate outer one. Metatarsus of anterior legs strongly

Plate 1. Apomyrma stygia, worker of the small kind (type nest series), scanning electron micrographs by $\mathrm{H}$. E. Hinton. A, head and part of truncus in oblique lateral view, $X$ 43. $\mathrm{B}$, head in oblique dorsal view, $X 49$. C, dorsal view of pronotum and adjacent structures, $X 104$; note reticulation of cervix and striation of mesonotum. D, back of head and cervix, dorsal detail, $X 248$. E, lateral view of pronotum and adjacent structures, $X 83$. $\mathrm{F}$, oblique dorsal view of posterior part of dorsal pronotum, mesonotum, and propodeal dorsum, looking caudad, $\times 104$. 

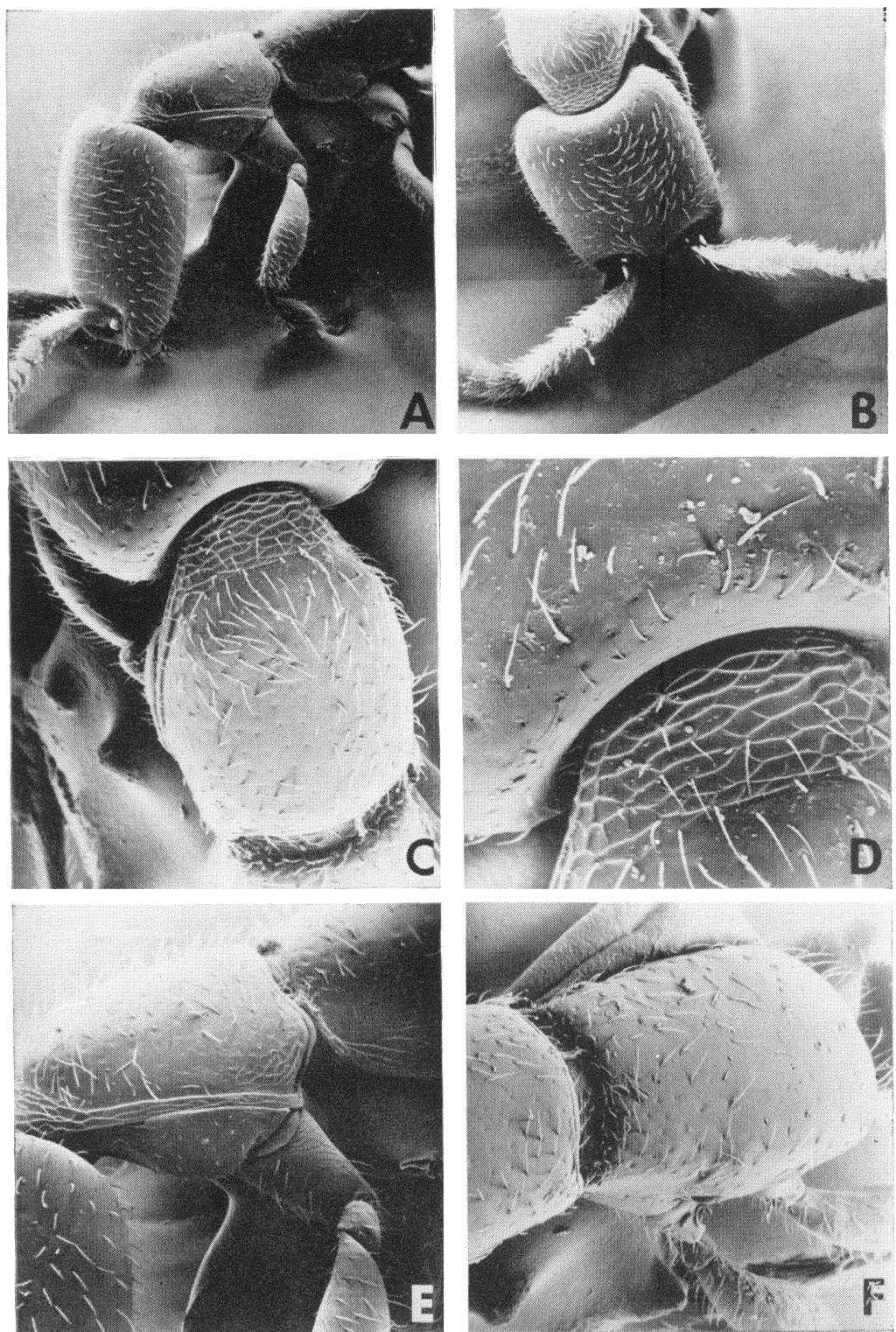

Plate 1 
curved, opposing the large pectinate tibial spur; other metatarsi straight, weakly clavate. Tarsal claws small, slender, simple.

Petiole with a massive subcubical node, a brief, slender, but distinct anterior peduncle, and a very short posterior peduncle. Both anterior and posterior faces of the node are vertical, and the petiole is connected to the gaster only by the narrowly strangulated connection of the posterior petiolar peduncle to the short anterior peduncle of the first gastric (postpetiolar) segment. Postpetiole (first gastric segment $=$ true abdominal segment III) reduced in size, only slightly broader than petiole; much smaller than the following segment, and showing a very slight beginning of constriction from the latter (constriction a little more distinct in the queen). Sternum of postpetiole especially reduced, only weakly convex and with only a suggestion of bilateral anteroventral processes on either side of a shallow anteromedian impression. Second gastric (IV abdominal) segment the longest, widest and deepest of the gaster; larger than the remaining apical segments taken together; these taper to a rounded apex from which issues a very long, slender, curved sting. Postpetiolar tergum and the terga of all succeeding segments of gaster easily and cleanly separable from sterna.

Entire body shining, smooth, with abundant small, distinct, spaced punctures on dorsum of head, becoming fewer and smaller on truncus and remainder of body; legs and antennal funiculae becoming more densely and finely punctulate apicad; cervix and a few other areas on sides of truncus and node loosely reticulate.

Entire body (except lower sides of truncus) and appendages covered densely (more sparsely on underside of petiole and gaster) with short, fine, pointed hairs.

Color ferruginous yellow; mandibles and appendages lighter yellow.

Queen, alate: Like the worker in general form of body, but more robust overall. Eyes well-developed, pigmented and moderately convex, with about ro facets across the greatest diameter, situated

Plate 2. Apomyrma stygia, same worker as in Plate 1, scanning electron micrographs by $\mathrm{H}$. E. Hinton. G, posterior part of truncus, oblique lateral view, $X 86 . \mathrm{H}$, petiole and associated structures, lateral view, $X 87$. I, closer view of propodal-petiolar articulation, showing details of sculpture and of spiracles, $\times 203$. J, lateral view of hind tibial apex, showing coarsely pectinate smaller spur lying over larger, broader, more regularly and finely pectinate medial spur, $X 203$. $K$, portions of the 3 apical segments of an antenna, showing reclinate peg-like sensilla and finer setae. $\times 428$. L, end of front tarsus, showing a tarsal claw, $\times 473$. 

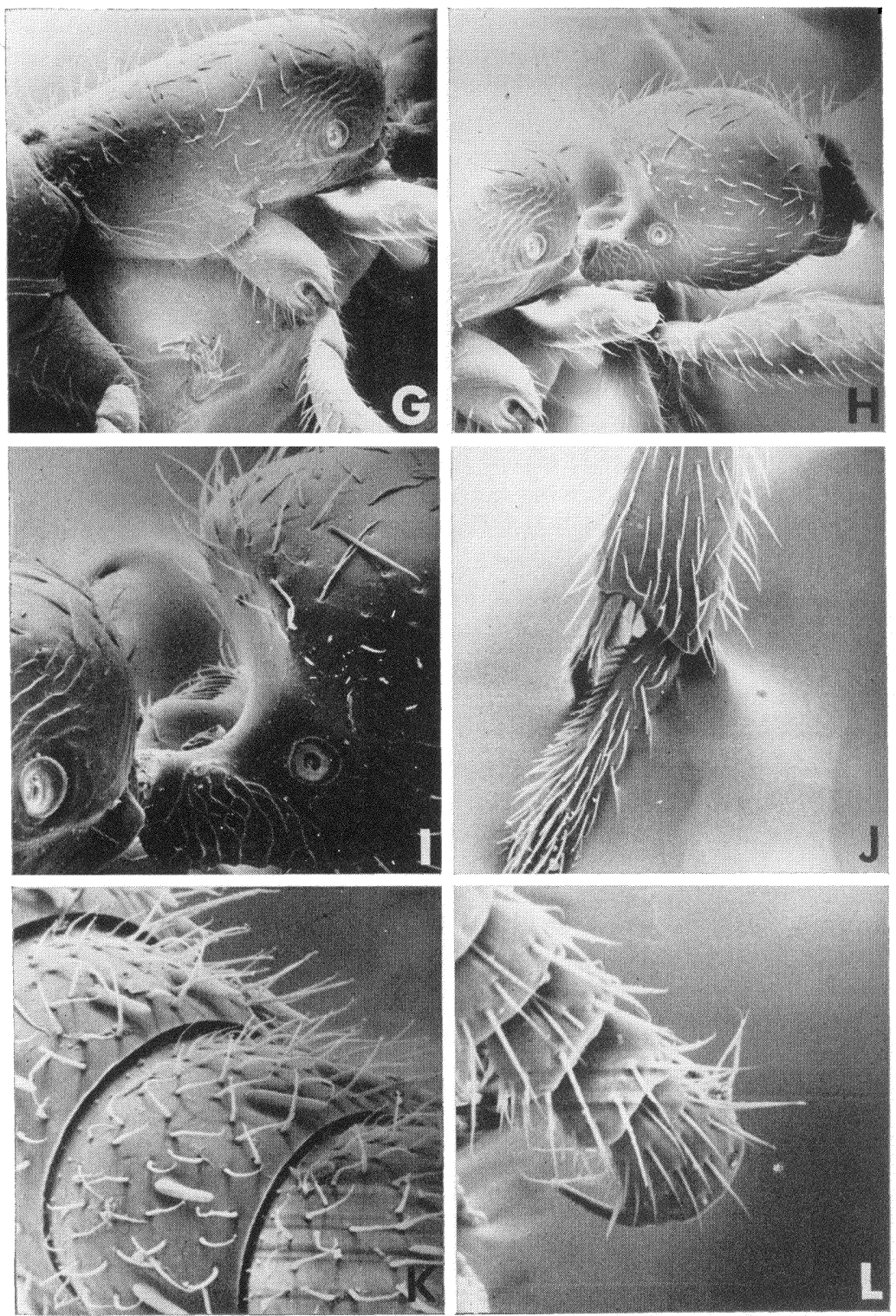

Plate 2 
far back, at about the posterior quarter of the head length. Ocelli developed, situated between compound eyes. Pterothorax well developed but nearly flat, continuing the nearly straight (very feebly convex) dorsal profile of the truncus as seen from the side. Scutum, prescutellum ( $=$ axillary area) and scutellum all developed, flat, the scutum without recognizable notauli or parapsidal furrows. Wings delicate, hyaline, microtrichiate.

The second and third free abscissae of Rs are wanting, creating a large cubital cell; $\mathrm{Mf}_{4}$ is completely lacking, and there is even a small gap left at its former origin at the angle between $\mathrm{Mf}_{3}$ and $r-m$, so that the cubital cell is not completely closed at its posterodistal corner (Fig. 7). Rs narrowly recurved into costal margin about halfway between pterostigma and wing apex, thus enclosing a fairly long radial cell ; except for Rs, apical half of wing membrane without veins. Hind wing narrow, acutely rounded, venation restricted to $\mathrm{R}+\mathrm{Sc}$, which fades out before reaching midwing; hamuli small and weak, 5 in number in the specimen counted; no anal lobe.

Petiolar node and gaster a little wider than in worker, and the incipient constriction between postpetiole and succeeding segment a bit more distinct. Form of body, sculpture, pilosity and color otherwise much as in worker (the pilosity may be slightly more abundant and a bit longer.)

Type species, by present designation:

\section{Apomyrma stygia species nov.}

Worker, small form, composite description - total length (TL) 2.0 - 2.2 mm, head length (HL) o.46-0.50 mm, head width (HW) $0.32-0.34 \mathrm{~mm}$, cephalic index (CI) 68-70, scape length $0.20-0.22$ $\mathrm{mm}$, hind femur length $0.22-0.24 \mathrm{~mm}$, length of trunk (WL) 0.59$0.69 \mathrm{~mm}$, length of petiole with anterior and posterior peduncles $0.27-0.28 \mathrm{~mm}$, length of petiolar node $0.20-0.2 \mathrm{I} \mathrm{mm}$, width of node 0.18-0.20 mm, length of postpetiole (first gastric segment) O.I6$0.19 \mathrm{~mm}$, width of postpetiole $0.23-0.26 \mathrm{~mm}$. Length of hairs about 0.0I-0.04 mm, mostly 0.02-0.03 mm. Hairs mostly erect, many inclined at different angles. The distribution of superficially reticulate areas on the cervix and lower sides of pronotum, on coxae, on sides of propodeum around spiracle, and on anterior sides of petiolar node are shown well in the scanning electron micrographs (Plates I, II). The SEM also shows the sunken, narrow mesonotum to be transversely striolate.

Worker, large form (from nest AA 3I5 NI) - TL 3.0-3.I 

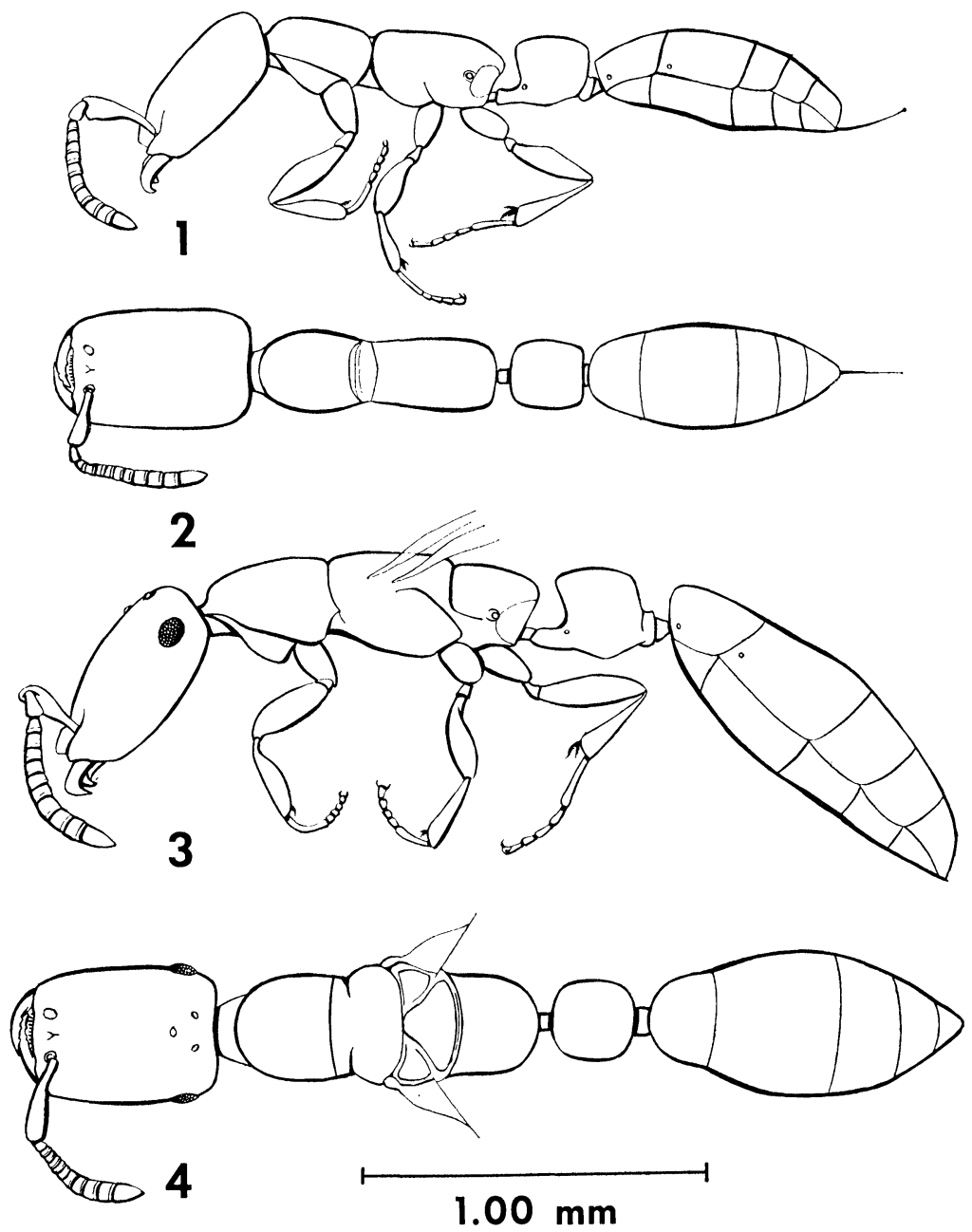

Figures 1-4, Apomyrma stygia sp. n., small form, worker and queen, habitus drawings, pilosity omitted. Fig. 1, worker, lateral view. Fig. 2, worker, dorsal view. Fig. 3, queen, lateral view, wings omitted. Fig. 4, queen, dorsal view, wings omitted. 


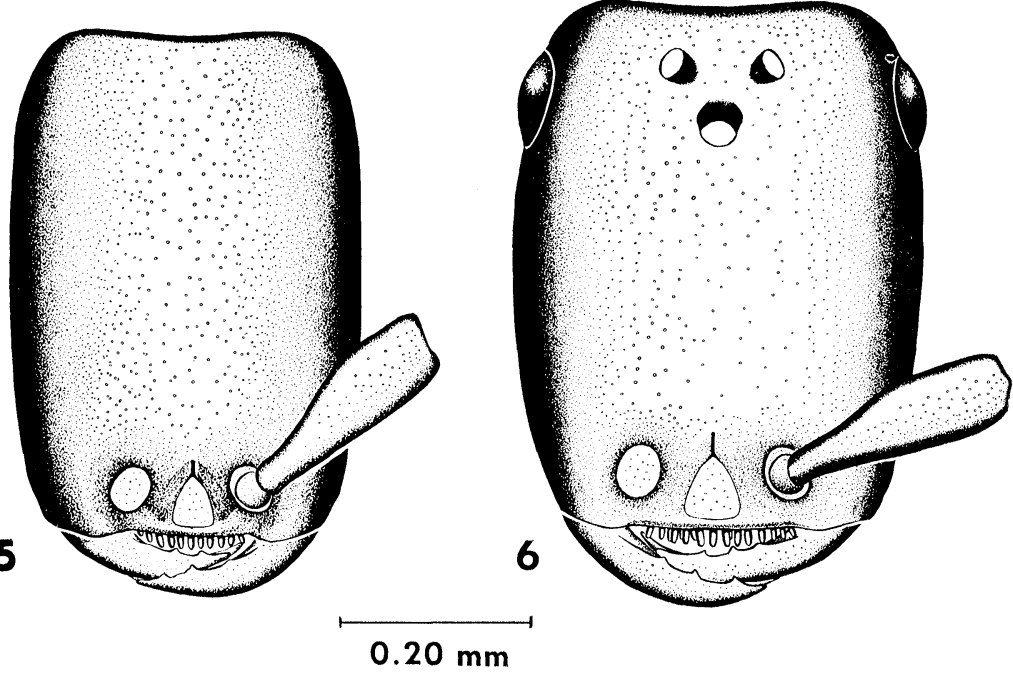

Figures 5-6, Apomyrma stygia sp. n., small form, heads in dorsal view, pilosity omitted. Fig. 5, worker. Fig. 6, queen.

mm, HL 0.62-0.65 mm, HW 0.47-0.50 mm (CI 76-77), scape L $0.29-0.30 \mathrm{~mm}$, hind femur L 0.35-0.36 mm, WL 0.9I-0.96 mm, petiole $\mathrm{L} 0.38-0.4 \mathrm{I} \mathrm{mm}$, petiolar node $\mathrm{L} 0.27-0.29 \mathrm{~mm}$, petiolar node $W 0.30-0.32 \mathrm{~mm}$, postpetiole $\mathrm{L} 0.25 \mathrm{~mm}$, postpetiole $\mathrm{W} 0.42$ mm.

Distinctly more robust than small form; head, truncus, petiolar node, postpetiole and rest of gaster all relatively wider. Color darker, medium ferruginous. Punctures on head a little more numerous and much more distinct, at least in part because of the darker ground color. Otherwise, the large form is very similar to the small form, and probably is no more than a size variant of the same species showing slight allometric tendencies.

Queen, alate small form (holotype), from nest of I 7 June, I968 TL $3.0 \mathrm{~mm}, \mathrm{HL} 0.57 \mathrm{~mm}, \mathrm{HW} 0.43 \mathrm{~mm}$, (CI 75), scape L 0.26 $\mathrm{mm}$, hind femur $\mathrm{L} 0.32 \mathrm{~mm}$, forewing L $1.95 \mathrm{~mm}$, WL $0.95 \mathrm{~mm}$, petiolar node $\mathrm{L} 0.27 \mathrm{~mm}$, petiolar node $W 0.30 \mathrm{~mm}$, postpetiolar node $\mathrm{L}$ 0.19 $\mathrm{mm}$, postpetiolar node $W 0.26 \mathrm{~mm}$, greatest diameter of compound eye $0 . \mathrm{I}$ I $\mathrm{mm}$.

Queen, dealate small form, from nest AA 3 I 8 NI - TL 2.7 mm, HL $0.54 \mathrm{~mm}$, HW 0.4. $\mathrm{mm}$ (CI 76), scape L $0.24 \mathrm{~mm}$, hind 


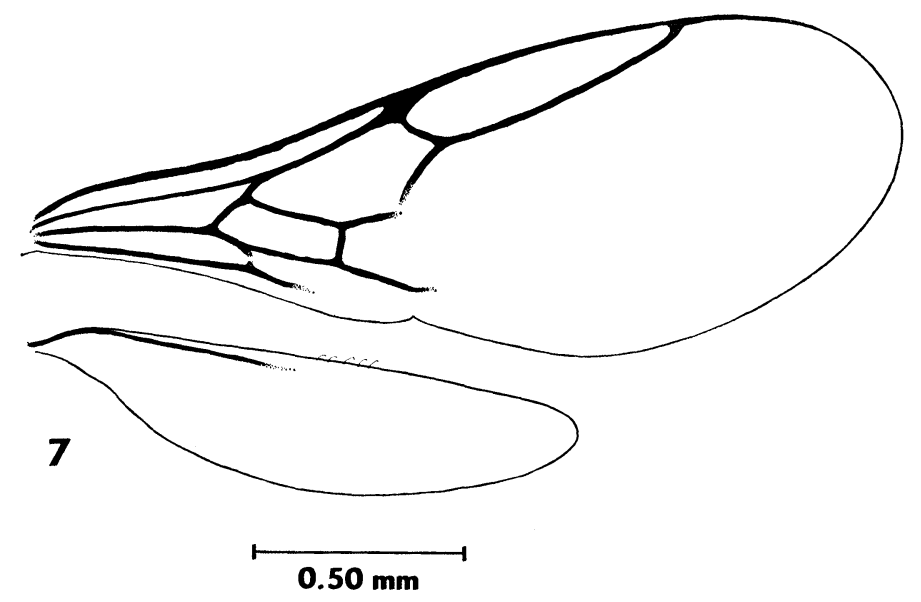

Figure 7, Apomyrma stygia sp. n., small form, wings of queen.

femur L $0.30 \mathrm{~mm}$, WL $0.94 \mathrm{~mm}$, petiolar node $\mathrm{L} 0.24 \mathrm{~mm}$, petiolar node $W 0.27 \mathrm{~mm}$, greatest diameter of compound eye $0.095 \mathrm{~mm}$.

Ergatoid - Two specimens from the type nest are intermediate between winged queens and workers from this nest series in size, and wings or wing stumps are absent. The mesonotum is reduced to a subquadrate piece. Compound eyes are present but smaller than in winged queens; 3 ocelli are present.

Male, pharate adult: removed from cocoon, which is similar in size and color to the small-form worker cocoons with which it was mixed in type nest. Pupal skin partly removed by needle. Total length (TL) about $2.8 \mathrm{~mm}, \mathrm{HL}$ about $0.4 \mathrm{~mm}$, WL about I.I $\mathrm{mm}$. The specimen is still pale, with compound eyes in the purple stage (greatest diameter $0.24 \mathrm{~mm}$ ), and only the first faint flush of tannish pigmentation showing, mainly on truncal dorsum. Numerous fine brownish points probably indicate the presence of an abundant fine pilosity. Details of smaller mouthparts cannot be made out, since the parts are still soft and transparent, but the mandibles are vestigial, small and triangular, with rounded apices, separated by nearly the whole width of the labrum. Details of middle front of head also obscure, but from what can be seen, not much different from the worker here. Antennae I3-segmented, with very short scape, funicular segments varying from about as broad as long to longer than broad; apical segment longest. Truncus as in Fig. I9; wings not yet unfolded. Petiole short, much higher and broader than long, 


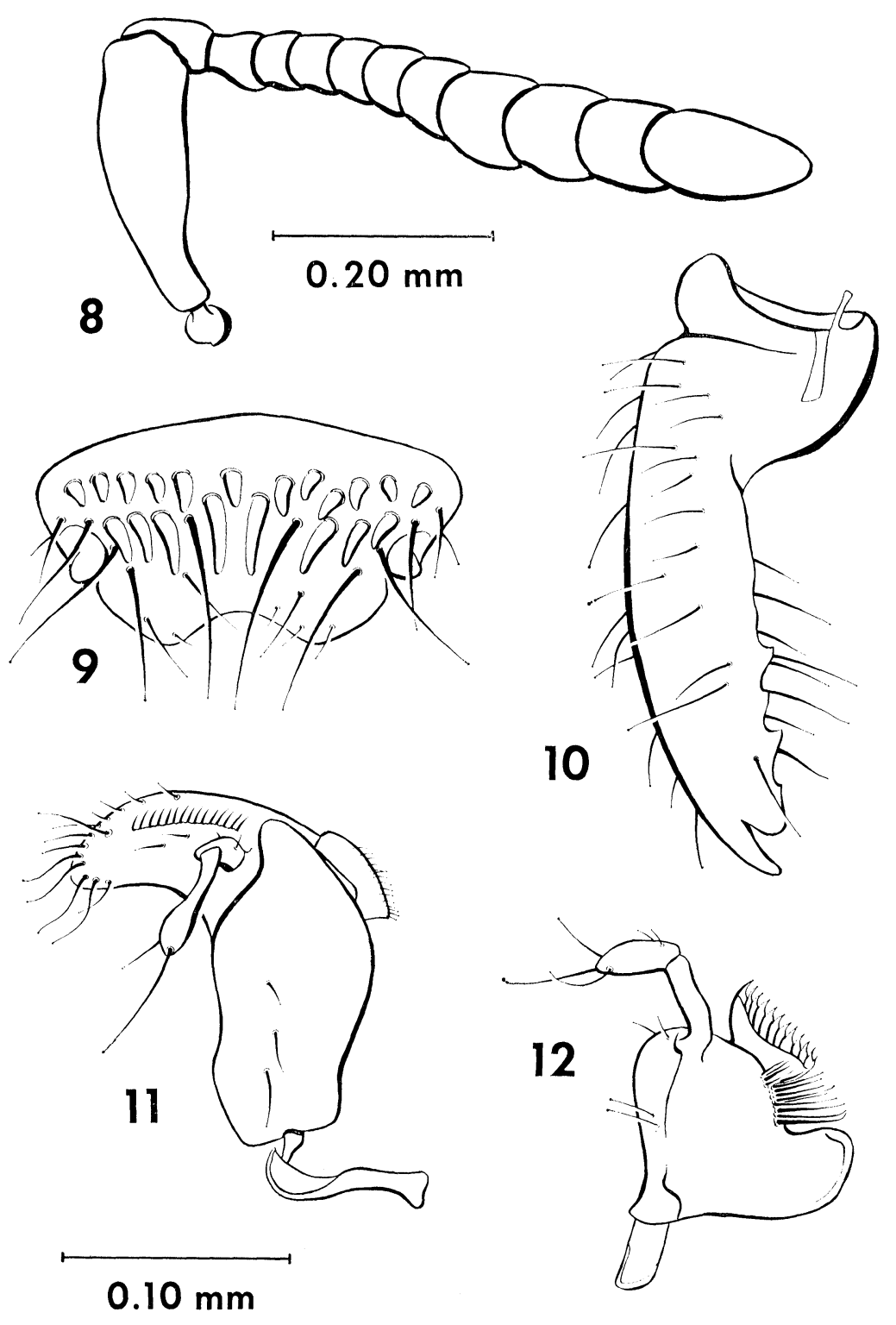


thick-squamiform, with a free steep, flat anterior face, but attached over nearly its entire posterior face to the next gastric segment (postpetiole). This petiole is an axially-compressed version of the usual amblyoponine pattern. Gaster not unusually long, tapering gradually toward apex; genitalia not distinct, and represented in Fig. I9 only as a rough approximation. The integument, as far as it is developed, seems relatively smooth and featureless overall, though, as mentioned above, the punctulation is apparently rather dense.

Pupae, worker, queen and male, enclosed in white cocoons, about 2.0 to $2.6 \mathrm{~mm}$ long in the small form and $3 . \mathrm{I}-3.5 \mathrm{~mm}$ in the large form, with conspicuous black meconial spot at one end.

Larvae to be described separately by George C. and Jeanette Wheeler in a paper accompanying this one.

The type nest and 3 additional samples all came from the vicinity of Lamto Field Station of the University of Abidjan, south-central Cote d'Ivoire. Lamto is off the main highway $50 \mathrm{~km}$ or so south of Toumodi, the nearest town of any size. The holotype and some paratypes are deposited in the Musée Nationale d'Histoire Naturelle, Paris. Other paratypes are placed in the Museum of Comparative Zoology at Harvard University, the British Museum (Natural History), the Muséum d'Histoire Naturelle of Geneva, Switzerland, and elsewhere.

\section{Bionomics}

So far, Apomyrma stygia has been found only in the vicinity of Lamto. This is a region where savanna of the "Guinean" type interdigitates with the gallery forest of the Bandama River and its tributaries. A. stygia, which almost certainly is completely subterranean (except possibly for nuptial flight or promenade), is found here only by digging in the soil of the gallery forest and the "unburned" savanna. Unburned savanna has been spared the passage of fire for at least 6 years, with the result that thick vegetation renders the microclimate at the surface similar to that of the humus level in the gallery forest. Up to the present, extensive digging in

Figures 8-12, Apomyrma stygia sp. n., small form, antenna and mouthparts of queen. Fig. 8, antenna. Fig. 9, labrum, external view. Fig. 10, right mandible, dorsal view. Fig. 11, left maxilla, external view; the maxillary comb has been drawn as seen through the transparent galea. Fig. 12, labium with left labial palpus, lateral view. 


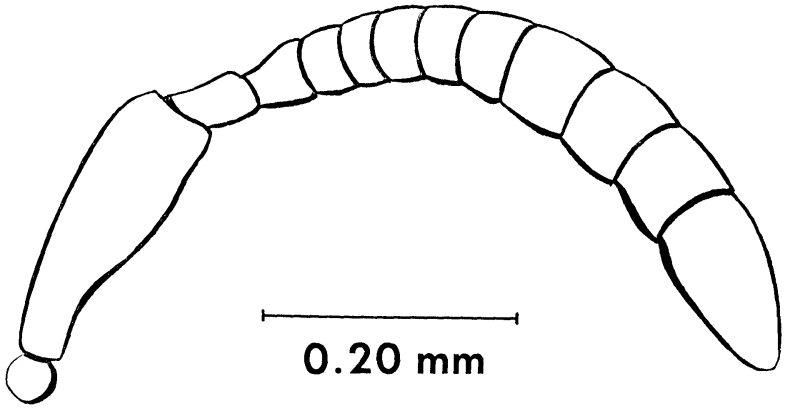

13
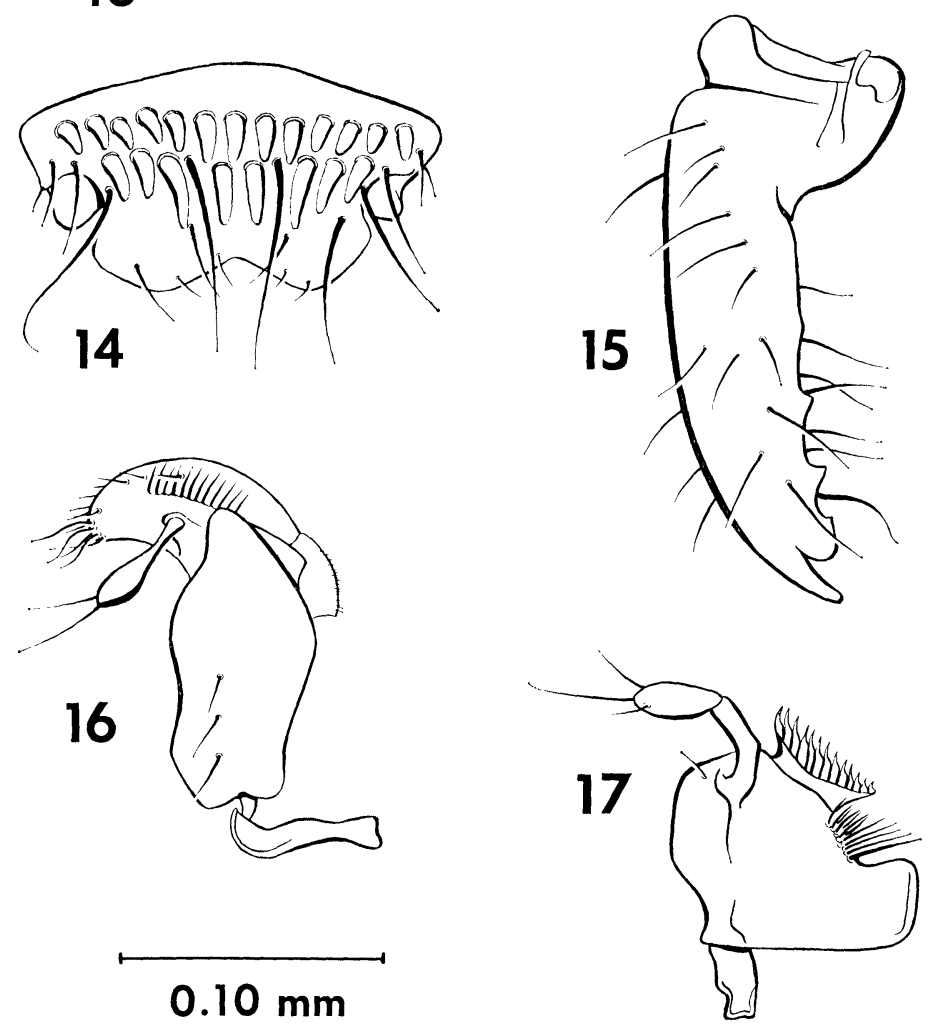
the annually-burned savanna (by Lévieux) has failed to turn up any samples of the new species, either as colonies or as single foraging workers. Apomyrma and the 5 or 6 Amblyopone species also found here constitute a remarkable and unexpected cryptic soil faunule, some members, perhaps all, of which belong to a centipede-feeding guild. This assemblage was revealed only by systematic large scale excavation and sifting of the soil in the course of intensive studies of savanna ant ecology conducted since I962 at Lamto.

Like the Amblyopone species at Lamto, Apomyrma stygia is probably best considered as an invader of the savanna via the gallery forest from the more extensive rain forest belt to the south. So far, excavations like those completed at Lamto have not been made in the rain forest proper, and have been made only to a limited extent in gallery forest. Apomyrma, like many of the other subterranean predatory ponerines, moves deep ( $30 \mathrm{~cm}$ or more) into the soil during the dry season (October to April), but during the rainy season it comes up to within $10 \mathrm{~cm}$ of the surface.

The 4 nests of $A$. stygia were all found during April-June 1968. Nos. AA 3I5 $\mathrm{NI}_{\mathrm{I}}$ and AA 3 I $8 \mathrm{NI}$ (both May ig68) were taken in sandy alluvial soil of the gallery forest of the Bandama River. 'The soil surface in each case, while tree-shaded, was bare of herbage. AA 3I $5 \mathrm{NI}$, a nest of nest fragment of the large form consisting of 12 workers and a single dealate queen, was taken about Io $\mathrm{cm}$ deep, and was found in the same meter quadrat as Amblyopone sp. near normandi. AA 3 I 8 NI, I5 workers and a dealate queen, was found ahout $15 \mathrm{~cm}$ beneath the surface and in the same meter quadrat as a colony of Amblyopone mutica.

The type nest (without code number) was taken I7 June I968; it and AA 285 N8 came from unburned savanna with dark clayey "terre noire" soil bearing a cover of the grass Loudetia simplex growing about I $\mathrm{m}$ high. The nest contained about 75 workers, 6 alate and 5 dealate queens, 2 ergatoids, and a few pupae and pharate adults of queens, males and workers, plus a few larvae of different sizes.

The type nest was $15-20 \mathrm{~cm}$ in diameter and $2 \mathrm{~cm}$ high, containing the brood, most of the adults, and cut-up remains of a geophilomorph

Figures 13-17, Apomyrma stygia sp. n., small form, antenna and mouthparts of worker. Fig. 13, antenna. Fig. 14, labrum, external view. Fig. 15, right mandible, dorsal view. Fig. 16, left maxilla, external view; the maxillary comb has been drawn as seen through the transparent galea. Fig. 17, labium with left labial palpus, lateral view. 


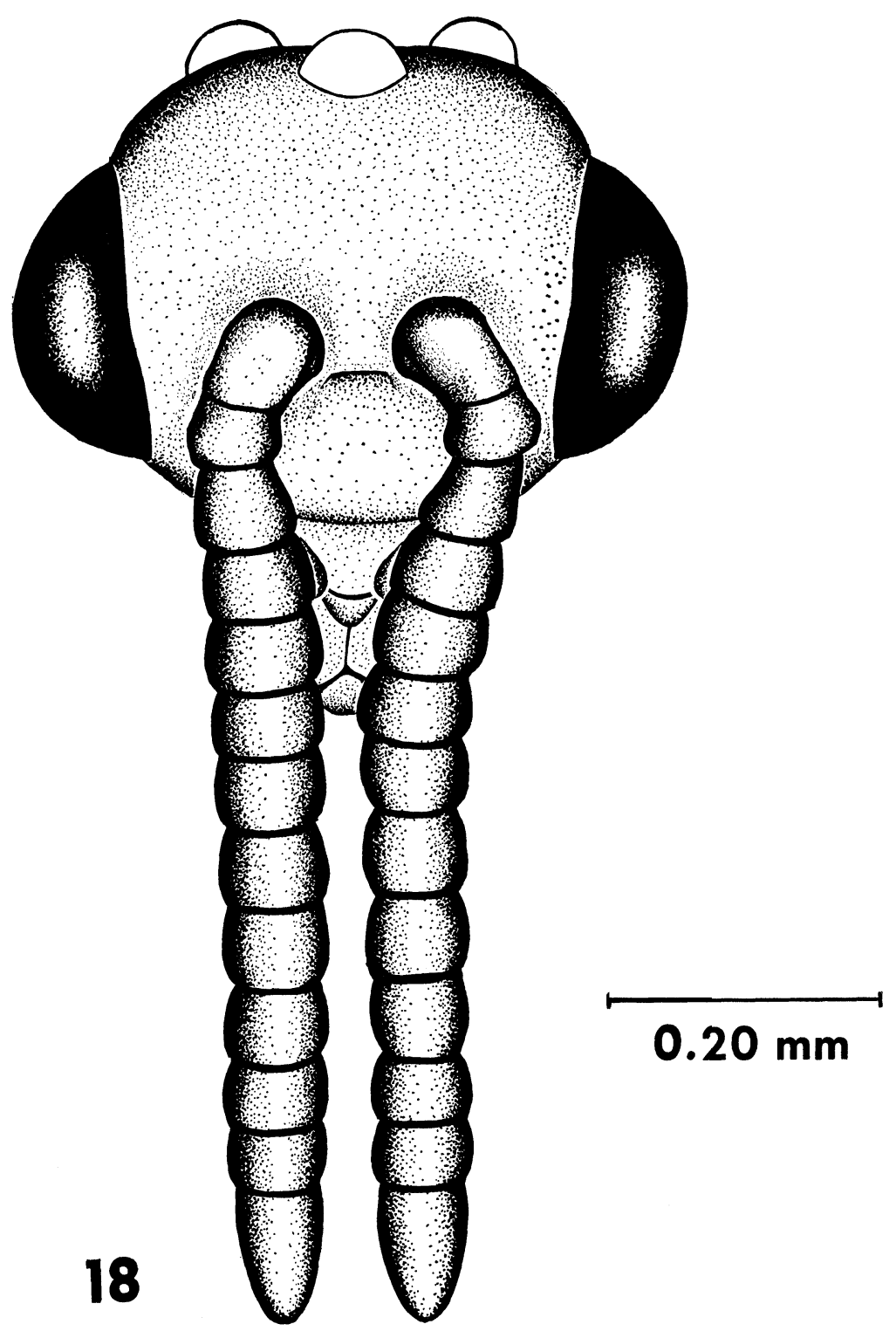

Figure 18, Apomyrma stygia sp. n., small form, head of pharate male in dorsal view, pilosity omitted. 


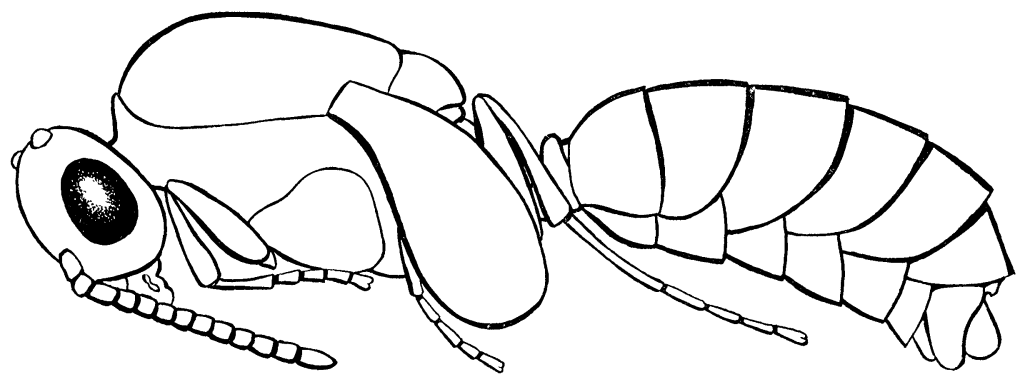

19

\section{$1.00 \mathrm{~mm}$}

Figure 19, Apomyrma stygia sp. n., small form, pharate male, habitus drawing, lateral view, pilosity omitted.

centipede determined by M. Demange of the Musée Nationale d'Histoire Naturelle, Paris, as belonging to genus Schendylurus. This suggests that Apomyrma, like a larger new species of Amblyopone found at Lamto, is a specialist predator of geophilomorph chilopods. Of course, direct observations on feeding are needed.

The colony did not occupy more than a part of the cavity, and it seems likely that the workers merely touched up a pre-existing hollow of some sort. From the main chamber ran several passages in different directions. Their diameter (less than $3 \mathrm{~mm}$ ), their position and lengths, as far as one could follow them, resembled the paths of vanished grass roots. After finding this nest, the soil was dug carefully for a meter around it and to a depth of $30 \mathrm{~cm}$, but no more specimens were found.

AA285 N8, found i6 April ig68, consisted of about 32 workers and a dealate queen from a small pocket about $20 \mathrm{~cm}$ deep.

The occurrence of winged sexual adults and pupae in mid-June suggests that Apomyrma has a nuptial season in late June, a little later than that assumed for Amblyopone species at Lamto.

\section{Taxonomic position}

This species is without much doubt related to Amblyopone. The 
head and truncus, while modified from the general amblyoponine form, nevertheless do not depart from it radically, and the extreme posterior placement of the queen's eyes is a "super-amblyoponine" character. However, the very deep constriction between the petiole and postpetiole, and the strong reduction (but without significant post-constriction) of the postpetiole, are traits that do set Apomyrma off very strongly from $A$ mblyopone. For a time, our instincts wavered in the direction of setting up a separate new tribe. In the end, the impressions of the collector (Lévieux), and his observation that Apomyrma follows the generalized amblyoponine habit of preying upon chilopods, pushed us to the conclusion that the new genus is really basically an amblyoponine. Larval characters (see following paper) confirm this placement. This conclusion also tends to follow the good rule of taxonomic parsimony, so we foreswore the establishment of a new tribe, even though the morphological definition of tribe Amblyoponini thereby loses most of its former sharpness based upon the lack of constriction between petiole and postpetiole. Actually, this character is partly transgressed by some species of the Australian genus Onychomyrmex, and an African morphocline including Amblyopone muticum also shows one kind of approach toward the constriction of the posterior part of the petiole in that genus.

\section{Appendix \\ Details of worker-female mouthparts}

Labrum (Figs. 9 and I4): Distal margin emarginate but without medial cleft; numerous slender, tapering setae inserted on the distal two-thirds of the external surface; two rows of stout peg-like setae inserted on the proximal half of the external surface.

Mandible (Figs. 1O, I5): Internal margin not distinctly divided into basal and masticatory components; provided with I apical and I subapical teeth, 3 to 4 denticles proximad of subapical tooth; numerous setae inserted on the dorsal and lateral surfaces and on the ventral surface of the internal margin.

Maxilla (Figs. I I, I6) : Maxillary palpus 2-segmented. Stipes subrectangular but drawn into a blunt point distally; usually 3 setae inserted on the proximal external face; lateral shoulder evident but smoothly rounded; external surface without conspicuous sculpturing. Galea typically formicoid in shape, with well developed maxillary comb; galeal crown inconspicuous and bearing numerous setae; 3 to 4 setae approximate a galeal comb in position of insertion but 
not in individual shape. Lacinia subquadrate with a rounded gonia and a pointed apex; lacinial comb reduced but continuous.

Labium (Figs. I2, I7): Labial palpus 2-segmented; premental shield lightly sclerotized and bearing only a few setae; subglossal brushes moderately developed, all included setae pointed; paraglossae and paraglossal sensory pegs absent.

\section{REFERENCES}

Gotwald, W. H., JR.

1969. Comparative morphological studies of the ants, with particular reference to the mouthparts (Hymenoptera: Formicidae). Mem. Cornell Univ. Agric. Exper. Sta., Ithaca, N. Y., 408: 1-150.

Wheeler, G. C. ANd J. Wheeler

1970. The larva of Apomyrma (Hymenoptera: Formicidae). Psyche, 77 (this issue, pp. 276-279.) 

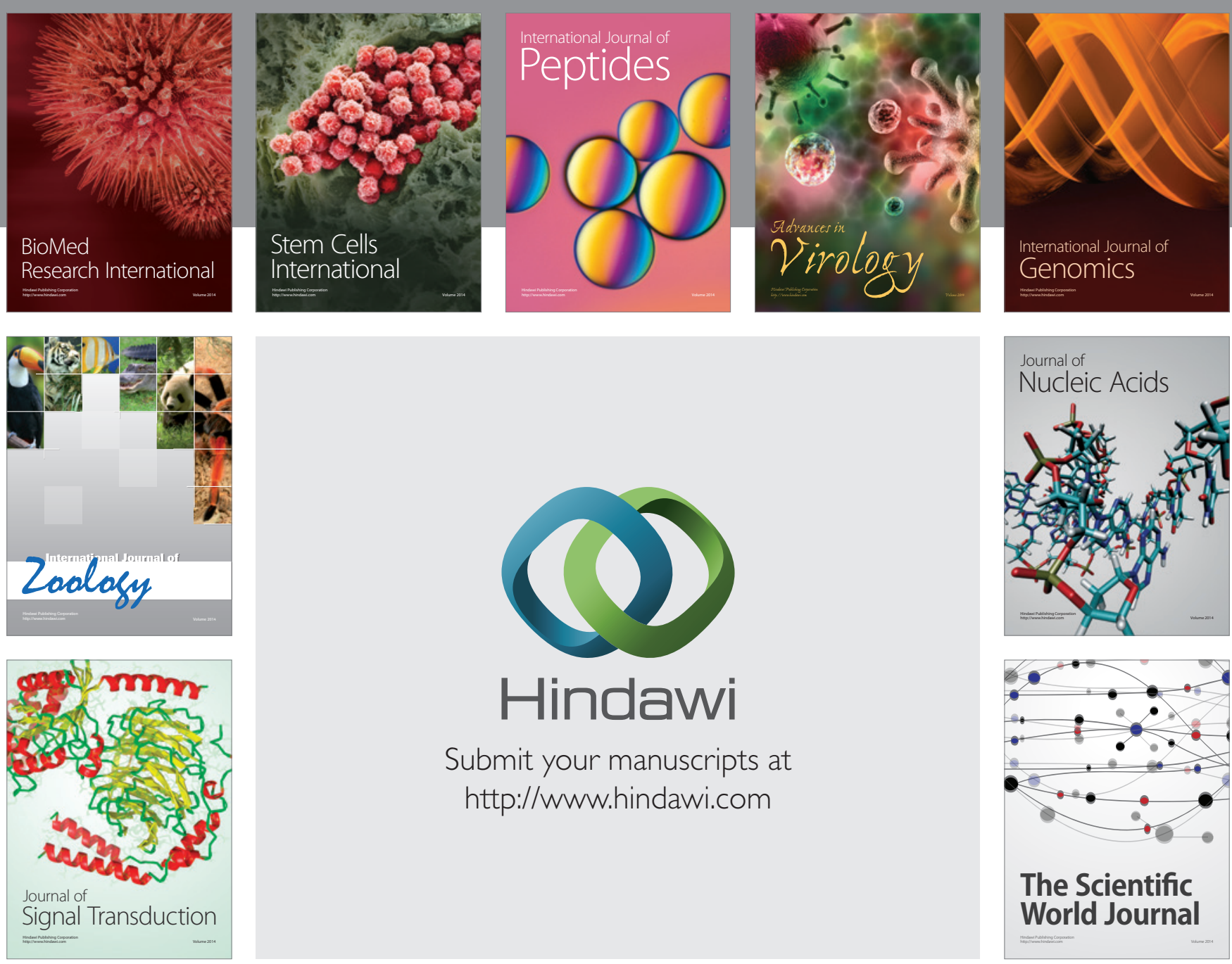

Submit your manuscripts at

http://www.hindawi.com
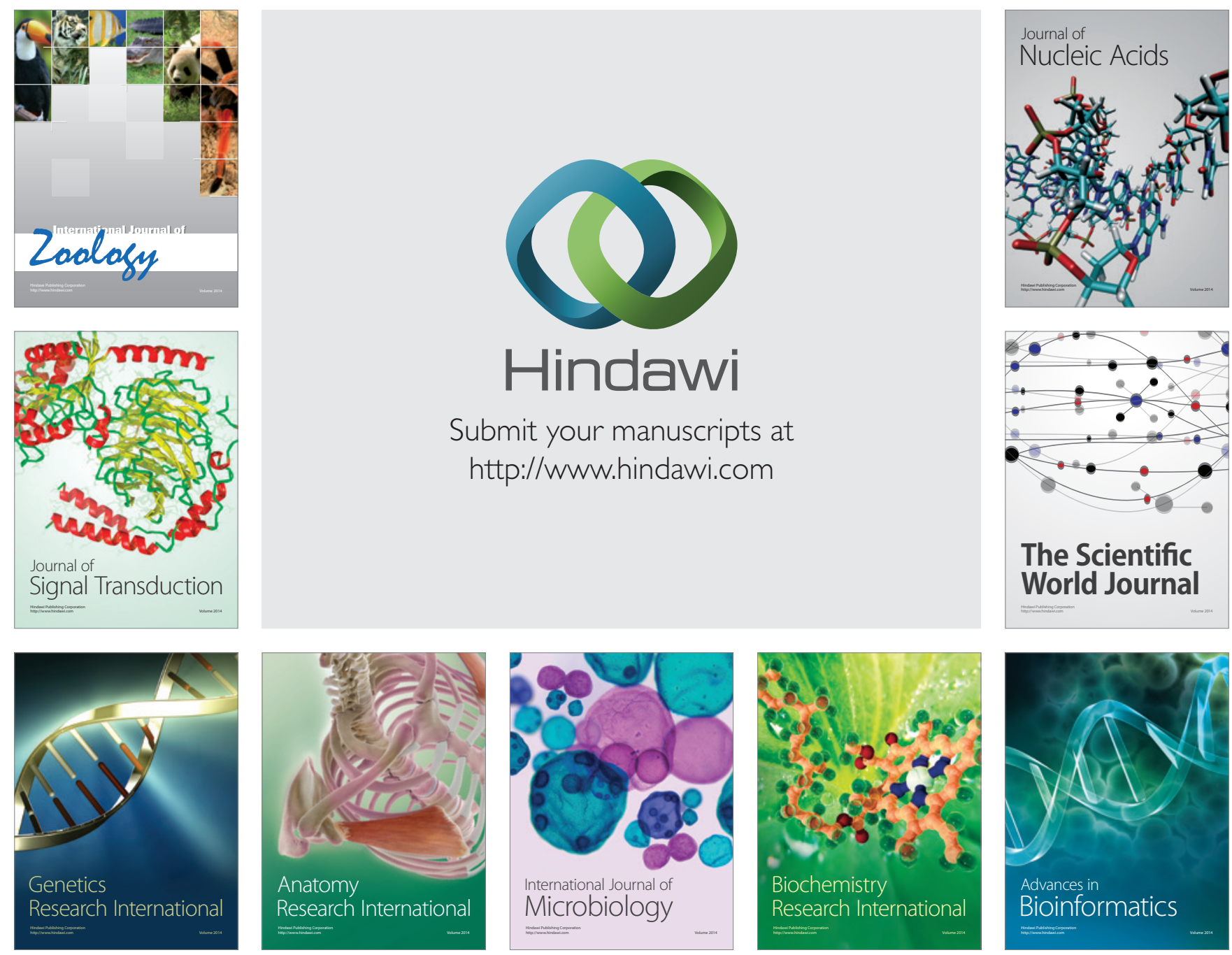

The Scientific World Journal
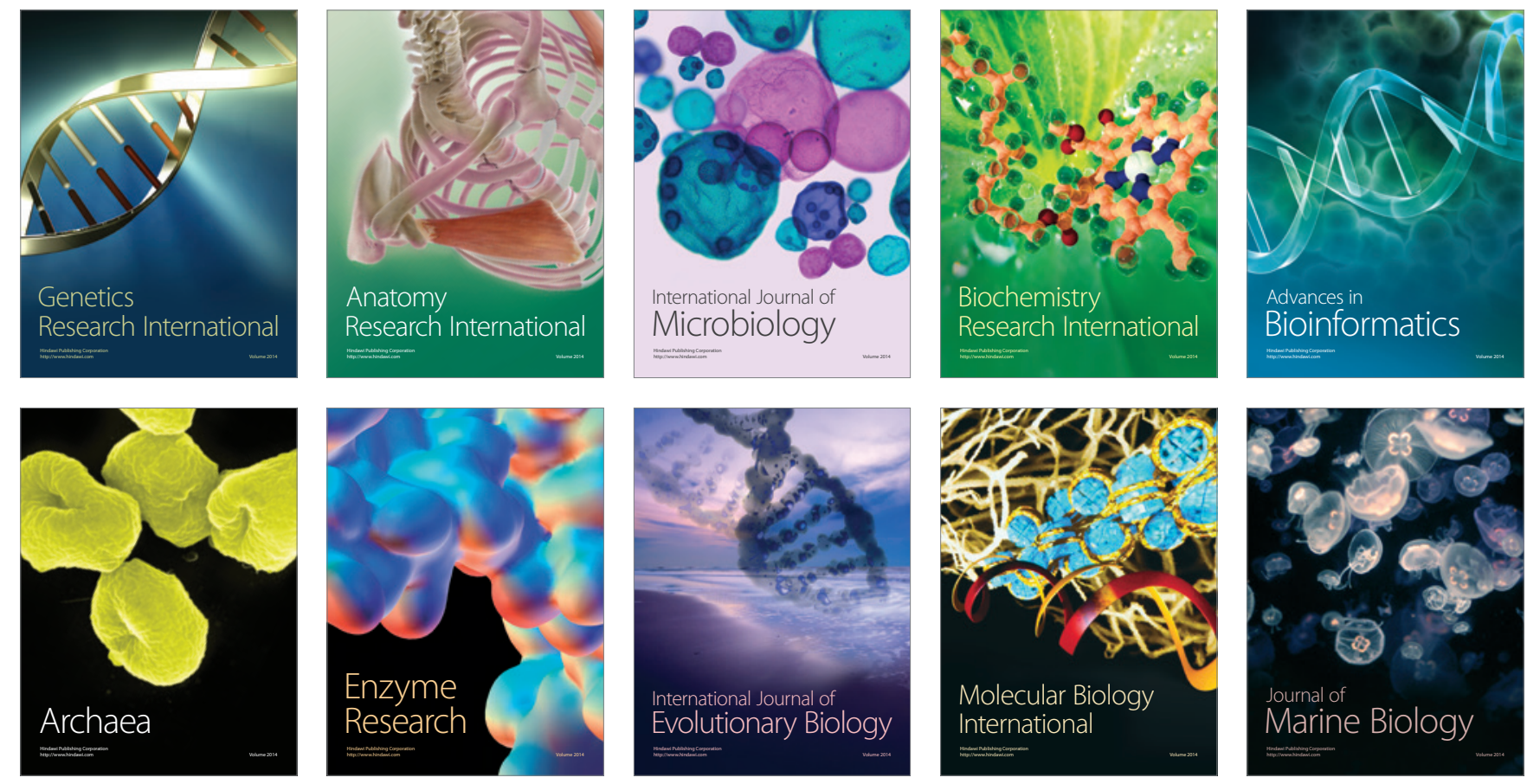